\title{
A noção de acontecimento discursivo
}

\author{
The notion of discursive event \\ Élcio Aloisio Fragoso ${ }^{1}$ \\ Universidade Federal de Rondônia
}

\begin{abstract}
- RESUMO: Neste artigo, tivemos como objeto de estudo o discurso romântico brasileiro e como material para análise recortes da obra Iracema, de José de Alencar. Nosso objetivo principal consistiu em compreender o acontecimento que era formulado por este discurso, à luz dos pressupostos teórico-metodológicos da Análise de Discurso, disciplina da interpretação - que assim foi concebida por Pêcheux (1990) e Orlandi (1996). Desse ponto de vista, pudemos elaborar que a escritura de Iracema explicitava o batimento entre memória e atualidade ao constituir-se enquanto o acontecimento da língua nacional, que se materializava com a emergência da construção do Estado-nação brasileiro, na segunda metade do século XIX. Dessa forma, este acontecimento promovia a ruptura com a língua portuguesa, instaurando uma individualidade - sentido que se historicizava com este acontecimento - da língua nacional.
\end{abstract}

- PALAVRAS-CHAVE: Acontecimento discursivo; Discursividade Literária; Iracema; Língua Nacional; Poesia.

- ABSTRACT: In this article, we had as object of study the Brazilian romantic discourse and as material for analysis clippings of José de Alencar\&\#39;s Iracema. Our main objective was to understand the event that was formulated by this discourse, in the light of the theoretical-methodological assumptions of Discourse Analysis, the discipline of interpretation - which was conceived by Pêcheux (1990) and Orlandi (1996). From this point of view, we could elaborate that Iracema writing explained the beating between memory and actuality by constituting itself as the event of the national language, which materialized with the emergence of the construction of the Brazilian nation-state in the second half of the nineteenth century. Thus, this event promoted the break with the Portuguese language, establishing an individuality - meaning that was historicized with this event - of the national language.

- KEYWORDS: Discursive Event; Literary discursivity; Iracema; National language; Poetry.

\section{Introdução}

Iniciaremos este texto dizendo que a noção de acontecimento está sempre relacionada à noção de memória discursiva, em análise de discurso. Pêcheux (1990, p. 17) define o acontecimento discursivo como o "ponto de encontro de uma atualidade $\mathrm{e}$ uma memória". Ou seja, trabalharemos com o acontecimento do discurso romântico no contexto de sua atualidade e no espaço de memória que ele convocava.

O discurso romântico, enquanto um acontecimento discursivo, intervém no real do sentido: ele é um gesto de interpretação. É preciso dizer, parafraseando Orlandi (2012, p. 57), que a memória discursiva é irrepresentável e o discurso romântico quando recorta esta memória, em algum ponto, produzindo um acontecimento, não "representa", produz um efeito, inserindo por seu gesto a memória em uma atualidade.

\footnotetext{
${ }^{1}$ Doutor em Linguística. Professor da Universidade Federal de Rondônia. E-mail: elciofragoso@unir.br
} 
Pensar o discurso romântico brasileiro enquanto acontecimento é se deslocar de uma perspectiva histórica (cronológica) em que uma população de enunciados permaneceria adormecida e os sujeitos, silenciados em uma história contínua/documental que se sustentaria em uma leitura espontânea e inequívoca, que é matéria de aprendizagem nas escolas. De nossa perspectiva, a história é produção de sentidos e está sujeita à interpretação. Por esta via, é que estamos entendendo o discurso romântico como um acontecimento em que a língua, sujeita à interpretação, é trabalhada em sua materialidade, no jogo como os seus significantes, produzindo o efeito de sentido de uma língua nacional, pela poesia. É no batimento entre uma memória (da língua portuguesa) e uma atualidade (a língua nacional) que vemos este acontecimento intervir no real do sentido, enquanto um gesto de interpretação.

\section{Notas e postulações: o acontecimento discursivo romântico brasileiro}

É justamente porque não entendemos a noção de formação discursiva como uma máquina discursiva de assujeitamento voltada à repetição, que estamos considerando que o discurso romântico constituiu-se na tensão entre a atualidade e a memória. A memória discursiva não é uma grade de leitura ou uma memória antecipadora do discurso em questão. Se assim concebêssemos a noção de discursividade, estaríamos desembocando em um apagamento do acontecimento, através de sua absorção em uma sobreinterpretação antecipadora (PÊCHEUX, 1999, p. 56).

$\mathrm{O}$ discurso romântico brasileiro não teve origem nele mesmo, o que significa dizer que ele não era romântico por si mesmo (por natureza), por essência. Nem estamos falando de um indivíduo psicológico que produzia o seu discurso, determinado por sua interioridade e sua emoção (subjetividades inerentes), mas, sim, da forma-sujeito histórica de direito, ou sujeito jurídico, definido pela sua sujeição ao Estado, através das leis (do Direito), isto é, de um indivíduo interpelado em sujeito pela ideologia e que dada a nossa formação social, num dado momento de sua história, o século XIX, o complexo de formações ideológicas e as formações discursivas que lhes correspondem, falaremos, então, de um sujeito que ocupava a posição de autor (literato) da língua nacional e que produzia o seu discurso, o romântico.

Tratava-se de um acontecimento que se constituía no batimento de uma atualidade e uma memória, e nisso reside a sua singularidade histórica. Este acontecimento que irrompia no Brasil, no século XIX, reorganizava sentidos, discursivizava o sentido de nacional, que fundava uma memória discursiva nacional. Portanto, o discurso romântico brasileiro significava este acontecimento de uma discursividade nacional (da nação, da língua e dos sujeitos identificados ao que era nacional).

O que era dito com este acontecimento e em quais condições de produção? Ele não era um discurso produzido do nada, nem um discurso que se situava fora da realidade histórica e simbolicamente constituída. Enquanto uma discursividade literária, este acontecimento se faz no confronto entre a formação discursiva literária portuguesa e a instauração de uma literatura (poesia) considerada nacional, confronto este que temos explicitado como constitutivo da escritura de Alencar. Este era o encontro entre a atualidade e a memória que o acontecimento discursivo romântico materializava (textualizava) e que buscaremos compreendê-lo neste texto.

$\mathrm{O}$ fato de chamarmos de acontecimento uma discursividade literária, isso terá consequências para este trabalho, dada a especificidade dessa discursividade, refiro-me ao jogo incessante do trabalho com a língua que é inerente ao funcionamento deste discurso. Deste ponto de vista, o acontecimento discursivo romântico dava visibilidade 
à relação entre estrutura (língua) e acontecimento (história), isto é, de como a história se inscrevia na língua para esta se significar. A relação entre a base (a língua) e o processo discursivo (a discursividade literária romântica).

O discurso de Iracema constituiu-se na tensão entre um dizer que irrompia e que nos "singularizava" e um dizer já instituído por meio de uma língua escrita e escriturada, isto é, queremos compreender o discurso de Iracema nesta tensão entre estrutura e acontecimento, entre descrição e interpretação.

Nesse sentido, temos no discurso romântico, tal como ele encontrava-se formulado em Iracema, ao mesmo tempo, um efeito de filiações sócio-históricas e um trabalho de deslocamento em seu espaço. Esse discurso (processo discursivo), a inscrição da história na língua, deixava ver o equívoco funcionando sob a evidência de um expressivismo poético, materialidade do sentido da língua nacional. Com o discurso romântico, institucionalizava-se a interpretação dessa língua e a inscrição do sujeito nacional na sua língua, estabilizava-se uma memória dessa língua.

As inúmeras metáforas e comparações que faziam alusão à natureza, em Iracema, sobredeterminavam o acontecimento, sublinhando sua equivocidade: "A virgem seguira o estrangeiro como a brisa sutil que resvala sem murmurejar por entre a ramagem" (ALENCAR, 2017, p. 9).

O sentido de singular, de único, só poderá ser melhor entendido, de nosso ponto de vista, se introduzirmos a noção de efeito de sentido. É, portanto, pela ideologia que podemos compreender o efeito de sentido da singularidade, materializado no discurso de Iracema. A materialidade do sentido é a sua singularidade, que, no caso do discurso de Iracema, esse batimento entre estrutura e acontecimento é o que vai conferir a existência material da singularidade da língua nacional.

Este acontecimento remetia a um conteúdo (nacionalista) ligado à construção de nossa identidade e a uma unidade nacional, ao mesmo tempo, perfeitamente transparente e profundamente opaco. Pêcheux (1990, p. 20) vai nos dizer que a novidade não tira a opacidade do acontecimento. Sobre o que este discurso falava, que leitura ele imprimia, que interpretação ele materializava? Que efeitos de sentido ele trabalhava? Em Iracema, a lenda do Ceará é uma metáfora nacional, pois ela transferia sentidos ao narrar a formação desse país, inscrição histórica no discurso. Como este acontecimento (o romântico) era interpretado pelos sujeitos autores que o movimentavam, que o formulavam em suas escrituras, ou seja, que o discursivizavam? Dessa forma, a noção de acontecimento, proposta por Pêcheux (1990), levou-nos à compreensão do Romantismo, não enquanto um conhecimento (discurso) já dado, como tendo um referente que precisava ser conhecido, mas sim enquanto um gesto de interpretação (ORLANDI, 1996), cuja materialidade era a singularidade da língua nacional trabalhada sob o efeito de sentido (evidente) do estilo literário romântico. Que leitura era esta que foi feita por estes autores, da posição em que ocupavam? Analisar este discurso é colocar-se na tensão entre descrição e interpretação, espaço onde podemos observar a relação entre o linguístico (estrutura) e o histórico (acontecimento), que constituía a materialidade específica deste discurso.

Nossa questão aqui não é buscar pelo referente deste discurso, mas sim pela tensão entre a descrição e a interpretação posta neste discurso, questão decisiva para a discussão que desenvolveremos neste artigo.

Em relação às discursividades literárias clássicas (o que temos é a discursivização do clássico, ou seja, da língua portuguesa significada e legitimada como clássica), a estabilização lógica de sentidos, a rigidez de suas regras, as normas estabelecidas e a formalidade da linguagem eram alguns dos efeitos de sentido evidenciados por estas formações discursivas que refletiam as formações ideológicas de 
um determinado momento da história da formação social brasileira. Nesse sentido, é que entendemos que o acontecimento da discursividade literária romântica expunha a língua à falha, à falta, discursividade esta constitutiva do sentido de transformação observado no "deslocamento" de colônia para um país independente (o Estado nacional), que tem uma unidade e uma identidade própria, relativamente à língua. A discursividade literária romântica é que produzia o efeito de sentido de nacional em relação ao nosso país. Era por meio desse nacionalismo/naturalismo que se dava fortemente a construção da nossa individualidade/identidade nacional. Como já dissemos, a discursividade literária romântica participava da construção da unidade de um Estado nacional. A nossa questão é de observar os sentidos que esta discursividade materializava ao nosso país, tendo em vista o momento determinado da nossa história (de nossa formação social) em que esta discursividade foi produzida. Mais importante do que falar em um país natural (em terra natal) é observar como esta discursividade romântica constituía este sentido, isto é, um sentido de nação. A ruptura que podemos notar que a discursividade literária romântica brasileira realizou será determinada por desfiliações históricas, em que jogavam as diferentes formações discursivas ligadas pelo interdiscurso, as relações de sentidos que determinavam a constituição e a instituição de sentidos concernentes à construção da unidade da língua e da nação brasileira.

Entender o discurso romântico como um acontecimento significa dizer que este discurso fez trabalhar outros sentidos, materializava o deslocamento de colônia para uma nação própria, relativamente à instituição de sentidos (a construção de uma referência) para esta nação. Este acontecimento discursivo filiava-se a redes de memória que trabalhavam sentidos de uma unidade nacional, enfatizando a terra natal e seus filhos, em um discurso nacionalista que incluía os que são nascidos, naturais da nação brasileira e excluía o diferente, o estrangeiro, enfim o de fora. Era esse nacionalismo ${ }^{2}$, ligado ao "sentimento" de amor à terra natal que víamos ser constituído com este acontecimento discursivo.

Não se trata aqui de pensar o nacionalismo enquanto essência, mas, sim, enquanto uma prática discursiva, isto é, a prática discursiva romântica. A construção do Estado-nação brasileiro na segunda metade do século XIX é uma realidade historicamente determinada e o nacionalismo do qual estamos falando, está relacionado a este fenômeno. Ele participava da construção histórica da formação social brasileira (da segunda metade do século XIX) com suas instituições, em que a unidade do Estado nacional se tornava visível. $\mathrm{O}$ discurso romântico brasileiro, quando pensamos em sua materialidade, possibilitava-nos ver a organização desses sentidos ${ }^{3}$ (o como se diz) e a direção para qual eles apontavam.

\footnotetext{
2 Interessante trazer aqui o trabalho de RODRÍGUEZ (2000) que, em sua tese, analisa os discursos nacionalistas sobre a língua guarani no Paraguai, discursos esses que se constituíram nas primeiras décadas do século XX, no contexto dos conhecidos movimentos de reivindicação novomundista surgidos na América Latina, e passaram a sustentar as políticas linguísticas oficiais adotadas no Paraguai a partir dos anos 1940 e 1950. A autora - que, após trazer duas direções possíveis como resposta para a pergunta que faz sobre a manutenção do guarani no Paraguai em tão larga escala, e os fatores que impossibilitaram a implantação efetiva do espanhol, fazendo com que o projeto cultural colonial, em grande medida fracassasse - vai trazer, com seu trabalho, um estudo em que analisa discursos nacionalistas que se constituíram nas primeiras décadas do século XX, para que se compreendam alguns equívocos apontados na segunda direção possível na explicação de que teria se constituído na sociedade local uma atitude diferente que teria feito com que ela não aceitasse essa imposição cultural e mantivesse a língua indígena, um gesto claramente independente nesse contexto colonial. Rodríguez (idem) lembra também que esses discursos de reivindicação nacionalista, por ela analisados, atualizavam elementos que, surgidos na tradição romântica, serviram de base para as formulações dogmáticas, xenófobas e racistas características das últimas décadas do século XIX, que seriam a matriz dos nacionalismos totalitários um pouco posteriores. (RODRÍGUEZ, 2000).

${ }^{3}$ Os sentidos, como nos diz Orlandi (1997, p. 11), "enquanto relação a, nunca existem em si, mas nas relações que se estabelecem em sua produção".
} 
Desse modo, esse discurso textualizava o singular, o próprio, relativamente à nação brasileira. Ao dizer, o romântico estava dando existência material à nação brasileira. Este discurso dava lugar para outros sentidos, estabelecidos por instituições próprias (com suas práticas) que significavam e legitimavam nossa identidade própria. De colônia para a condição de Estado nacional, interrompiam-se - quando entendemos a relação entre linguagem e a formação social - certas filiações discursivas, certos funcionamentos, a referência ao Estado português, etc.

Não estamos afirmando que o discurso romântico rompia, empiricamente falando, com o Estado português e suas instituições, mas sim, que este discurso formulava nossa independência, nossa singularidade, por meio de um imaginário que levava em conta a construção de uma unidade (imaginária) para o Estado nacional brasileiro. Como este discurso fez esta ruptura? Entendemos que o discurso romântico materializava a unidade do Estado nacional.

Falar em interromper um processo colonial, não significa afirmar uma "passagem direta" de uma realidade para outra (de colônia a um país independente, em suas evidências), pois não estamos falando em realidade empírica, mas como sendo historicamente determinada. Significa dizer que, por um lado, as instituições portuguesas materializavam memórias, estabilizavam sentidos, disciplinavam o conhecimento e praticavam discursos. E, por outro lado, essas instituições (com seus discursos/seus conhecimentos e suas memórias) estão na base da constituição de outras instituições e dos deslocamentos de seus discursos.

Estamos propondo que se pensem as condições de produção do discurso romântico brasileiro. $\mathrm{O}$ acontecimento histórico de nossa independência, seguido da construção do Estado-nação brasileiro, além de um contexto mais amplo que compreende as condições sócio-histórica e ideológica devem ser considerados quando falamos do acontecimento discursivo romântico brasileiro. Este discurso é parte da construção da realidade historicamente determinada de nossa independência. Desse modo, não é de nossa independência em si mesma que falaremos, mas da maneira como o discurso romântico brasileiro significou o sentido de independência, por meio de um gesto de interpretação.

Entretanto, este acontecimento discursivo, embora se constituísse nas condições de produção da independência do Brasil, no século XIX (que formação social era esta e como ela se organizava neste determinado momento, o século XIX?), produzia sentidos determinados pelas formações discursivas em relação de contradição no interior de uma mesma formação discursiva, a romântica. Desse modo, conforme observaremos, ao analisar a materialidade de Iracema, era a memória discursiva colonialista que produzia efeitos de sentido na produção desse discurso.

Quando falamos em "independência", queremos nos deslocar de uma leitura historiográfica na qual esta palavra já está interpretada. A história para análise de discurso não é linear, cronológica. Ela é produção de sentidos. Não se trata de pensar a "independência do Brasil" de forma solta e sob a evidência de um sentido de liberdade (livre) que se instituiria com o "ideal romântico". O discurso romântico funda esse "ideal" de nação que se sustenta nesse sentido de "independência", como liberdade. Uma nação independente, ideal, que exalta o seu passado, em um movimento de sentido nacionalista, descartando, desse modo, a relação de dominação, estabelecida entre colonizador e colonizado. O sentido de nação/nacionalismo, que era formulado pelo discurso romântico brasileiro, era determinante de um posicionamento conservador que defendia a unidade linguística em detrimento de uma diversidade, em que o amor/a paixão à nação (o nacionalismo) prenunciava um discurso excludente, totalitário e autoritário que se desenvolveria no século XX. Trata-se de pensar o discurso romântico 
como um discurso fundador (ORLANDI, 1993) da nação brasileira e que vai nos imprimir uma memória nacional.

Este acontecimento que irrompia ainda na primeira metade do século XIX - no círculo literário da época, em condições específicas de circulação, pois a imprensa chegava ao Brasil no começo deste mesmo século - realçava nossas terras, a nação, a nossa língua e o brasileiro. Não é de um acontecimento novo que estamos falando, muito menos de um acontecimento verdadeiro, real. Em sua materialidade (discursiva), efeitos de sentido eram produzidos numa relação entre o linguístico e o histórico. Esta relação produzia efeitos no modo mesmo como o sujeito da posição de autor da língua se apropriava dessa língua (portuguesa) no Brasil. O modo de funcionamento da língua é histórico e ideológico, conforme já dissemos neste trabalho. Quando estamos falando de uma língua nacional, estamos falando, na realidade, em efeitos de sentido. Vejamos como Pêcheux (1990) formula a questão da discursividade como estrutura ou acontecimento:

Não se trata de pretender aqui que todo discurso seria como um aerólito miraculoso, independente das redes de memória e dos trajetos sociais nos quais ele irrompe, mas de sublinhar que, só por sua existência, todo discurso marca a possibilidade de uma desestruturação-reestruturação dessas redes e trajetos: todo discurso é o índice potencial de uma agitação nas filiações sócio-históricas de identificação, na medida em que ele constitui ao mesmo tempo um efeito dessas filiações e um trabalho (mais ou menos consciente, deliberado, construído ou não, mas de todo modo atravessado pelas determinações inconscientes) de deslocamento no seu espaço (...). (PÊCHEUX, 1990, p. 56).

De nossa perspectiva, quando falamos do discurso romântico brasileiro, estamos falando já de uma certa interpretação do real, ou seja, estamos falando de um discurso inscrito em uma certa memória, e em certos trajetos sociais. A possibilidade de interpretar, diz-nos Pêcheux (1990), está ligada à existência do discurso-outro como espaço virtual de leitura desse enunciado ou dessa sequência.

Ainda sobre a tensão entre descrição e interpretação, no interior da análise de discurso, Pêcheux (1990, p. 55) vai acrescentar:

Esse discurso-outro, enquanto presença virtual na materialidade descritível da sequência, marca, do interior dessa materialidade, a insistência do outro como lei do espaço social e da memória histórica, logo como o próprio princípio do real sócio-histórico. E é nisto que se justifica o termo de disciplina de interpretação, empregado aqui a propósito das disciplinas que trabalham neste registro (PÊCHEUX, 1990, p. 55).

$\mathrm{O}$ acontecimento discursivo romântico remetia a um conteúdo em que se exaltava a identidade nacional, conteúdo este que se apresentava ao mesmo tempo como transparente e profundamente opaco, conforme já dissemos no início deste texto. $\mathrm{Na}$ verdade, o acontecimento do discurso romântico produzia sentidos para o seu referente, por meio de uma memória, ao invés de pensarmos, como na literatura se faz, que este acontecimento tratava de uma forma poética o seu objeto. O poético já é também produção de (efeitos) sentidos, por meio de um gesto de interpretação estético.

Interessante é observar também como este acontecimento discursivo, legitimado pela instituição literária romântica (formação discursiva dominante), validava suas 
proposições (tornando-as verdadeiras). $\mathrm{O}$ que o acontecimento discursivo romântico descrevia, como já foi dito acima, deve ser tomado em redes de memória, dando lugar a filiações identificadoras, ou seja, não se tratava de "aprender" o que esse discurso dizia, mas, sim, de determinar o lugar e o momento da interpretação deste dizer.

O discurso romântico formulava o acontecimento da língua, de como ela era singularizada, por meio de uma discursivização literária que reorganizava sentidos de uma memória da língua nacional, ao instituir uma escrita e uma escritura da mesma. Essa discursivização literária sobre a língua nacional é o acontecimento que chamamos de Romantismo que se materializava no batimento entre língua (estrutura) e história (acontecimento), tendo por efeito o estilo: o modo próprio desta língua funcionar que é histórica e ideologicamente determinado.

A nação brasileira deixava de ser regulada por meio de relações estabelecidas e vindas (apenas) diretamente do Estado português e suas instituições, e isso pode ser observado na instituição literária (por meio de sua prática discursiva), pois conforme o discurso romântico brasileiro ${ }^{4}$, reclamavam-se outros sentidos (e outras filiações), verificava-se uma tensão, uma disputa (a divisão - o político) pela língua, pela individualidade da nação brasileira. No entanto, isso não significava dizer que o Estado português e suas instituições não estavam mais relacionados com o que se fazia ou se (re) produzia aqui no Brasil. A nosso ver, a relação de subordinação, de desigualdade, de contradição produziu e produzirá seus efeitos tanto no Brasil, quanto em Portugal. $\mathrm{O}$ que estamos afirmando aqui é que a ruptura que o discurso romântico brasileiro (a discursividade literária romântica brasileira) promovia dava visibilidade ao acontecimento da língua no Brasil. Certamente que não estamos dizendo que se tratava de uma nova língua, mas sim de que a língua portuguesa era ressignificada por um gesto de interpretação determinado por outras formações discursivas em que jogava também, sem dúvida, a formação discursiva portuguesa. O que significa dizer que no discurso romântico brasileiro jogavam outros efeitos de sentido que se materializavam em outras construções, que significavam a nossa língua. Tem-se, dessa forma, outro funcionamento discursivo, que consideraremos aqui como uma discursividade que inaugurava um modo próprio de significar a língua. Uma diferença que tomava forma na materialidade do discurso romântico - acontecimento da língua no Brasil. Era em relação a este processo mais amplo que podemos compreender os sentidos (e suas relações) na produção desse discurso (o romântico).

Ao analisarmos o discurso de Iracema, vemos que o sujeito, da posição da qual falava, produzia seu discurso evocando uma memória colonizadora (a memória colonialista das línguas indígenas), filiando-se a esta memória, identificando-se com ela. Se é verdade que esta memória regulava o discurso romântico, também, por outro lado, podemos observar um deslocamento provocado pela ruptura e pela constituição de um discurso próprio, sob o efeito ideológico de uma liberdade individual (o discurso liberal), materializada nos efeitos de sentido que se instituíam ao brasileiro, à língua nacional, à nação brasileira e ao estilo romântico. Era sob este efeito de sentido que se fundava uma discursividade da nação brasileira.

O que o discurso de Iracema dizia no seu contexto de atualidade e no espaço de memória que ele convocava? Esses dizeres que foram produzidos por autores (a autoria nesta época é complexa, sendo o autor, muitas vezes, ao mesmo tempo gramático, historiador, literato, professor, político etc.) da literatura, no século XIX, era o acontecimento que remetia a um conteúdo relacionado a nossa identidade nacional, e que queremos compreendê-lo aqui na tensão entre a descrição e a interpretação. Não

\footnotetext{
${ }^{4}$ Discursividade literária que se fundava e que formulava a língua de uma certa maneira, constituindo-se em uma escritura da língua nacional (ou seja, em uma interpretação desta língua).
} 
ficaremos na evidência deste discurso, na evidência de um sentido subjetivo/pessoal. Para nós, o importante é compreender o funcionamento desse discurso, em relação ao real da língua e ao real da história. É o acontecimento da língua nacional que queremos descrever/interpretar neste trabalho.

No discurso romântico, também vemos a possibilidade da língua nacional irromper com seus matizes (sua materialidade linguístico-histórica), escapando às regularidades próprias da língua portuguesa de Portugal, ou seja, a essa memória da língua portuguesa (sua escrita), expondo-se à falha, ao diferente, à falta. Era esse batimento entre a memória e o atual que vemos ser trabalhado no discurso romântico, acontecimento discursivo da língua nacional. Este acontecimento fazia a língua se inscrever na história para se significar, constituindo-se em uma materialidade em que estrutura e acontecimento se chocavam; um discurso que rompia com sentidos, com o referente da língua portuguesa, e a língua se significava na relação ideológica (o imaginário) com o mundo natural e puro como está descrito em toda a obra de Iracema, de José de Alencar. Essa era a historicidade do sentido de que estamos falando no discurso de Iracema. A materialidade desse discurso é histórica e ideológica:

\footnotetext{
Além, muito além daquela serra, que ainda azula no horizonte, nasceu Iracema.

Iracema, a virgem dos lábios de mel, que tinha os cabelos mais negros que a asa da graúna, e mais longos que seu talhe de palmeira.

O favo da jati não era doce como seu sorriso; nem a baunilha recendia no bosque como seu hálito perfumado.

Mais rápida que a corça selvagem, a morena virgem corria o sertão e as matas do Ipu, onde campeava sua guerreira tribo, da grande nação tabajara.

O pé grácil e nu, mal roçando, alisava apenas a verde pelúcia que vestia a terra com as primeiras águas (ALENCAR, 1865, p. 5).
}

O modo como a língua era trabalhada pelo discurso romântico explicitava, para nós, esta relação entre estrutura e acontecimento, resultando em uma materialidade própria, que é histórica e ideologicamente determinada, como já dissemos anteriormente. A materialidade desse discurso dava forma à relação entre língua (estrutura) e exterioridade (história, ideologia). Uma língua que tem seu referente construído pelo discurso romântico, formulado em Iracema.

Iracema era parte desta escritura da língua nacional, pois, nesta obra, Alencar se propunha a escrever nesta língua e a praticá-la, discursivamente falando. Nesta obra, havia toda uma preocupação em descrever/interpretar a língua nacional. Ou seja, o sujeito autor se inscrevia na sua escritura, no seu discurso. Tratava-se de uma escritura que evidenciava esta língua, que a singularizava pela subjetividade, como o traço que inscrevia os sujeitos nacionais nessa língua. Portanto, língua e sujeitos singularizavamse por esta subjetividade, na escritura de Iracema. Procuramos mostrar o funcionamento desse discurso (de Iracema) no processo de constituição desse efeito de sentido subjetivo, na construção dessa escritura da língua nacional. Essa língua se legitimava pela instituição literária que a representava imaginariamente em relação à construção de uma unidade (imaginária) do Estado brasileiro. Essa língua materializava as relações de poder em jogo no complexo das formações ideológicas à época, o que consistia em dimensionar o significado da instituição literária e de sua prática discursiva, na segunda metade do século XIX. O poético, do modo como o entendemos na análise de discurso, aparecia aí como as possibilidades dessa língua de se significar, de jogar com seus significantes. O que podemos ler em Pêcheux (1990, p. 51) ao retomar Milner (1987): 
"nada da poesia é estranho à língua, - nenhuma língua pode ser pensada completamente, se aí não se integre a possibilidade de sua poesia."

Essa língua nacional (ou o efeito de sentido dessa língua) tinha um modo próprio de organização que era determinado pelo processo de enunciação que constituía as relações entre o linguístico e o seu referente. Daí falarmos em uma língua (a nacional) própria, visto que sobre o linguístico (significante) se constituiu toda uma significação historicamente determinada que tornava possível um outro funcionamento dessa língua; dessa forma, quando falamos em uma língua nacional, estamos, na realidade, afirmando que se tratava de um efeito de sentido (que é ideológico) dessa língua.

Compreender o discurso romântico não significa querer saber o que os autores, com suas produções, quiseram dizer, mas sim tomá-lo em redes de memória dando lugar a filiações identificadoras.

\section{Conclusão}

Em nossas reflexões, procuraremos mostrar, ao analisar a materialidade discursiva de Iracema, que já existia uma interpretação investida ali, enquanto um gesto (ideológico) que surge como tomada de posição. Entretanto, esse gesto de interpretação realizado pelo autor romântico (autor da língua nacional) só foi possível em relação à desfiliação histórica à rede de memória clássica, por um lado, e à inscrição, por outro lado, na formação discursiva romântica que instituiu a posição de sujeito autor da língua nacional. É assim que entendemos o acontecimento discursivo romântico brasileiro.

O acontecimento discursivo romântico fez a língua, passível de jogo, materializar-se diferentemente, sob outras construções que funcionarão sob o efeito de sentido da singularidade da língua nacional. Não quisemos aqui realizar uma descrição formal ou estilística das construções linguísticas deste acontecimento, mas, sim, pretendemos mostrar como a história se inscreve na língua fazendo esta se significar.

É, em relação ao poder do Estado burguês, sustentado pelo sistema jurídico concentrado em um único foco (por meio de sua forma logicista) e a forma de negociação da diversidade, em que ele se reveste ao mesmo tempo, que buscamos compreender o acontecimento discursivo do Romantismo brasileiro (PÊCHEUX e GADET, 2004, p.38).

Em suma, podemos dizer que o discurso literário clássico tinha um funcionamento que estava relacionado à forma da organização social daquele determinado momento (século XVI ao XVIII). Desse modo, não falaremos em regras ou normas rígidas, como são formalmente definidas e que o discurso literário fala em um estilo clássico/retórico. De nossa perspectiva, essa era a materialidade linguísticohistórica do discurso literário clássico. A língua era trabalhada ideologicamente e essa rigidez do discurso clássico era a materialidade da ideologia (dominante) no discurso. $\mathrm{O}$ funcionamento da língua estava articulado à forma da organização social da época, ou seja, estamos falando de uma escritura burguesa, de uma língua que se escrevia, que se fechava para os sentidos, que refletia a classe minoritária e privilegiada da época, por isso um discurso que excluía a divisão, a diversidade, em nome de um discurso seletivo, para uma minoria. A repetição formal materializava a imutabilidade do sentido, em outras palavras, a impossibilidade do deslocamento de sentido, por meio de um efeito de sentido universal.

\section{REFERÊNCIAS}


ALENCAR, J. de. Iracema. Ministério da Cultura - Fundação Biblioteca Nacional departamento Nacional do Livro. [online] Disponível em:

http://objdigital.bn.br/Acervo_Digital/Livros_eletronicos/iracema.pdf. Acesso em: 24 set. 2017.

GADET, F; PECHEUX, M. A língua inatingível: O discurso na história da linguística. Campinas: Pontes, 2004.

MILNER, J-C. O amor da língua. Porto alegre, Editora Artes Médicas, 1987

ORLANDI, E. P. (Org.) Discurso fundador: a formação do país e a construção da identidade nacional. Campinas: Pontes, 1993.

Apresentação. In: INDURSKY, F. A fala dos quartéis e outras

vozes. Campinas, Editora da Unicamp, 1997.

Editores, 2012.

Discurso em análise: sujeito, sentido, ideologia. Campinas: Pontes

Petrópolis: Vozes, 1996.

Interpretação, autoria, leitura e efeitos do trabalho simbólico.

PÊCHEUX, M. O discurso: estrutura ou acontecimento. São Paulo: Pontes, 1990.

ZUCCOLILLO, C. M. R. Língua, nação e nacionalismo: um estudo sobre o guarani no Paraguai. 2000. 254f. Tese (Doutorado em Linguística) - Instituto de Estudos da Linguagem da UNICAMP. Universidade Estadual de Campinas, São Paulo.

Recebido em: fevereiro de 2019. Aprovado em: maio de 2019.

Como citar este trabalho:

FRAGOSO, É. A. A noção de acontecimento discursivo. Traços de linguagem. V.3, n.1, p. 47-56, 2019. 